\title{
The Perspective of a Breast Cancer Patient: A Survey Study Assessing Needs and Expectations
}

Amulya Prakash ${ }^{1}$, Muhammad Sardar ${ }^{1}$, Nasreen Shaikh ${ }^{1}$, Sindhura Inkollu ${ }^{1}$, Mary Danish ${ }^{2}$, David J. Sharon ${ }^{3}$, Shira Goldberg ${ }^{4}$

1. Internal Medicine, Monmouth Medical Center, Long Branch, USA 2. Oncology, Monmouth Medical Center, Long Branch, USA 3. Oncology, Monmouth Medical Center, Leon Hess Cancer Center, Long Branch, USA 4. Hospice and Palliative Care, Monmouth Medical Center, Long Branch, USA

Corresponding author: Amulya Prakash, amulya.prakash.md@gmail.com

\section{Abstract \\ Background}

Patient satisfaction is one of the key indicators of health care quality. We aim to identify patient's needs and expectations in a breast cancer clinic to provide patient-centered care and better overall satisfaction.

\section{Methods}

A 17-item survey was administered to 110 patients at a breast cancer clinic. The survey was designed after a thorough literature review and approved by an oncologist and a palliative care physician.

\section{Results}

Self-reported knowledge about the disease was reported adequate by $90.9 \%$ of our patients yet only $55.45 \%$ of our patients could identify the stage of their cancer. More education was desired by $32.7 \%$ of patients including various treatment options (29\%), common complications (24.5\%), prognosis (26.3\%) and risk factors (11.8\%). The majority of our patients were having some form of cancer-related emotional stress and physical symptoms. The majority of our patients (57.27\%) wanted their oncologist to address social/emotional issues and $25.45 \%$ felt the need for more focus on physical symptoms in their subsequent visits. End-of-life (EoL) care discussions were considered an integral component of overall care by $29 \%$ of our patients. Components of EoL care discussions that patients stated they could benefit from included prognosis (27.27\%), life expectancy (29\%), the treatment effect on the quality of life (22.7\%), palliative care (9\%), hospice (10.9\%), advance directives (11.8\%), and family involvement in medical decision-making (13.6\%). There was a difference noted regarding their EoL care discussion based on the stage of cancer. Patients with early-stage disease wanted their oncologists to decide on the frequency of this discussion (72.7\%). Patients with advanced disease wanted EoL care discussion to be done more frequently as initiated by them or their oncologist or if there's a change in the treatment plan.

Received 06/22/2020

Review began 06/24/2020 Review ended 07/05/2020 Published 07/13/2020

\section{() Copyright 2020}

Prakash et al. This is an open access article distributed under the terms of the Creative Commons Attribution License CC-BY 4.0., which permits unrestricted use, distribution, and reproduction in any medium, provided the original author and source are credited.

\section{Conclusions}

A discrepancy between self-reported and actual knowledge in breast cancer patients emphasizes the need for patient education. Most patients rely on their oncologists for their diagnosis-related emotional and social issues. Surprisingly, more than a quarter of our patients consider EoL care discussions important even though the majority of our patients were healthy and having stage I and II disease.

Categories: Oncology

Keywords: breast cancer research, breast cancer outcomes, health communication, psycho-oncology, integration of palliative care service

\section{Introduction}

Breast cancer is the most common cancer among women in the United States and worldwide, excluding nonmelanoma skin cancers. As per the National Cancer Institute, estimated new cases of female breast cancer in 2019 were 268,600 which is $15.2 \%$ of all new cancer cases in the United States. The lifetime risk of developing this cancer in a woman is approximately $12.8 \%$ at some point during their lifetime, based on the data from 2014-2016 [1]. However, with recent advancements in screening methods, diagnostic modalities, and treatment options, relative survival has improved from $74.6 \%$ in $1975-1979$ to $90.6 \%$ in 2006 [2].

Diagnosis and treatment of breast cancer patients are complex with common principles modified by patient's unique issues. Breast cancer patients may be broadly divided into three groups: a) those with early-toadvanced-stage disease, i.e., those for whom adjuvant therapies may be offered, b) those with metastatic disease and c) those who are breast cancer survivors (BCS). 


\section{Cureus}

Patient's experience of breast cancer, throughout the continuum of their disease, will influence their "quality of life" [3]. This will be strongly influenced by their underlying understanding of their diagnosis, treatment, and prognosis. It is to that end that we devised the questionnaire utilized in this study. We attempted to better elucidate patient's knowledge, understanding and insight of their disease, and its treatment, and the impact it has had on their physical and psychological health. Our goal as health care providers (HCP) is to enhance the quality of our patient's medical as well as psychological outcomes. To that end, an enhanced understanding of our patients' underlying insights into their disease will guide us to their improved psychological well-being. At the same time, a well-informed patient would be able in a better way to voice their concern and guide their provider in their care. The first step, therefore, in this process, is to get a "snapshot" of the degree of their understanding.

\section{Materials And Methods}

Patients were identified who were enrolled in our breast cancer clinic for treatment or follow-up. A 17-item survey was administered to 110 patients using a convenience sampling method over 12 months. The survey was designed after an extensive literature review with the help of an oncologist and a palliative care specialist and waived by Monmouth Medical Center Institutional Review Board (IRB). The questionnaire was designed to assess the patient's knowledge, the impact of diagnosis, and treatment on physical and psychological health, end of life (EoL) care planning (Figures 1-3).

1 of 3

I. Current understanding of your condition and desire to know more

1) How do you describe your current knowledge about your condition?

\begin{tabular}{|l|l|l|}
\hline Adequate & Not Adequate & Not sure \\
\hline
\end{tabular}

2) Answer the following about your condition to the best of your knowledge?

\begin{tabular}{|l|l|l|l|}
\hline Diagnosis & Current treatment & Stage & Prognosis (likely course) \\
\hline & & & \\
& & & \\
\hline
\end{tabular}

3) Would you like to be educated more about your medical condition

\begin{tabular}{|l|l|}
\hline Yes & No \\
\hline
\end{tabular}

4) Which of the following components you think you need more information about.

\begin{tabular}{|l|l|l|l|}
\hline $\begin{array}{l}\text { Risk factors, } \\
\text { genetic } \\
\text { predisposition) }\end{array}$ & $\begin{array}{l}\text { Prognosis of your } \\
\text { condition in general }\end{array}$ & $\begin{array}{l}\text { Common complications } \\
\text { from your condition/ } \\
\text { treatment }\end{array}$ & $\begin{array}{l}\text { Various treatment options with } \\
\text { their effectiveness and side } \\
\text { effects }\end{array}$ \\
\hline
\end{tabular}

II. Psychological and Social Aspects

5) Do you have any of the following as a result of the condition and/or treatment

\begin{tabular}{|l|l|l|l|l|l|l|}
\hline Anxiety & Fear & Un-certainty & Sadness & $\begin{array}{l}\text { Effect on } \\
\text { personal /family } \\
\text { life }\end{array}$ & $\begin{array}{l}\text { Effect on professional } \\
\text { life/work } \\
\text { performance }\end{array}$ & Any other \\
\hline
\end{tabular}

6) Do you want your oncologist to initiate a discussion regarding these issues? \begin{tabular}{|l|l|}
\hline Yes & No \\
\hline
\end{tabular}

7)What would you want your oncologist to do if you face such issues related to your condition and/or treatment for it?

\begin{tabular}{|l|l|l|l|l|}
\hline Manage them & $\begin{array}{l}\text { Let your primary } \\
\text { care physician } \\
\text { manage them }\end{array}$ & $\begin{array}{l}\text { Referral to a } \\
\text { psychotherapist }\end{array}$ & $\begin{array}{l}\text { Referral to a Social } \\
\text { worker }\end{array}$ & $\begin{array}{l}\text { Referral to a Nurse } \\
\text { Navigator }\end{array}$ \\
\hline
\end{tabular}

FIGURE 1: Sample survey questionnaire page 1 


\section{Cureus}

III. Physical Symptoms related to the condition

8) Do you currently have following symptoms related to your condition and/or the treatment you are on for it

\begin{tabular}{|l|l|l|l|l|}
\hline Pain & Fatigue & Nausea & Vomiting & $\begin{array}{l}\text { Others-please } \\
\text { specify }\end{array}$ \\
\hline
\end{tabular}

9) Do you think there is a need to pay more attention to these symptoms in your subsequent visits?

\begin{tabular}{|l|l|}
\hline Yes & No \\
\hline
\end{tabular}

IV. End of Life Care Planning.

10) Do you think end of life care discussions with your oncologist is an integral component of your overall care?

\begin{tabular}{l|l} 
Yes & No
\end{tabular}

11) Have you ever had a discussion about end of life care planning with your oncologist?

\begin{tabular}{|l|l|l|}
\hline Yes, and within past 12 months & Yes, but not within past 12 & Never
\end{tabular}

12) Please select the components of the end of life care planning you think you need to have a discussion with your oncologist? You may select multiple options

\begin{tabular}{|c|c|c|c|c|c|c|c|}
\hline $\begin{array}{l}\text { Prognosi } \\
\mathrm{s}\end{array}$ & $\begin{array}{l}\text { Life } \\
\text { expectanc } \\
y\end{array}$ & $\begin{array}{l}\text { Effect of } \\
\text { treatment } \\
\text { on quality } \\
\text { of life, } \\
\text { functional } \\
\text { status and } \\
\text { productivit } \\
y\end{array}$ & $\begin{array}{l}\text { Your } \\
\text { preference } \\
: \\
\text { Extending } \\
\text { survival or } \\
\text { improving } \\
\text { Quality of } \\
\text { life }\end{array}$ & $\begin{array}{l}\text { Palliativ } \\
\text { e Care }\end{array}$ & $\begin{array}{l}\text { Hospic } \\
\text { e }\end{array}$ & $\begin{array}{l}\text { Advance } \\
\text { directive/ } \\
\text { Resuscitation } \\
\text { status } \\
\text { (Chest } \\
\text { compressions } \\
\text {. Intubations) }\end{array}$ & $\begin{array}{l}\text { Involvemen } \\
t \text { of family } \\
\text { in medical } \\
\text { decision } \\
\text { making, } \\
\text { Power of } \\
\text { attorney }\end{array}$ \\
\hline
\end{tabular}

13) When would you want to have these discussions

\begin{tabular}{|l|l|l|l|}
\hline $\begin{array}{l}\text { At } \\
\text { Diagnosis/Initiation } \\
\text { of treatment }\end{array}$ & $\begin{array}{l}\text { When your Oncologist } \\
\text { think it is appropriate }\end{array}$ & When you request it & $\begin{array}{l}\text { Only when it may affect the } \\
\text { treatment plan }\end{array}$ \\
\hline
\end{tabular}

14) How frequently?

\begin{tabular}{|l|l|l|}
\hline Once is enough & At a regular interval as mutually & At every appointment \\
\hline
\end{tabular}

FIGURE 2: Sample survey questionnaire page 2 


\section{Cureus}

\begin{tabular}{|l|l|l|}
\hline & $\begin{array}{l}\text { decided by you and your } \\
\text { oncologist }\end{array}$ & \\
\hline
\end{tabular}

\section{Patient satisfaction}

14) How satisfied are you about all your needs being addressed at regular follow-up appointments with your Oncologist. Rate on a scale of 1-10 (with 10 being the highest level of satisfaction)

\begin{tabular}{|l|l|l|l|l|l|l|l|l|l|}
\hline 1 & 2 & 3 & 4 & 5 & 6 & 7 & 8 & 9 & 10 \\
\hline
\end{tabular}

\section{Survey Questions}

15) How beneficial do you think this survey would be in communicating your needs and expectations to your Oncologist? Rate on a scale of 1-10 (with 10 being most effective)

\begin{tabular}{|l|l|l|l|l|l|l|l|l|l|}
\hline 1 & 2 & 3 & 4 & 5 & 6 & 7 & 8 & 9 & 10 \\
\hline
\end{tabular}

16) Did the questions of the survey cause any emotional stress?

\begin{tabular}{|l|l|}
\hline Yes (please specify the question) & No \\
\hline
\end{tabular}

\section{FIGURE 3: Sample survey questionnaire page 3}

Most of our patients were insured. The majority of them were English speakers in addition to other languages. Patients were approached by medical residents and research coordinator to fill out the survey. Nurse navigators were present to facilitate the process. Surveys were read out loud for patients with vision problems. Patients were also allowed to take the survey home and bring it back during the next visit.

\section{Results}

For a detailed overview of the patient's preference, see Table 1. Of all the included patients, $13.63 \%$ were stage $1,13.63 \%$ were stage $2,12.7 \%$ were stage $3,16.36 \%$ were stage $4,14.5 \%$ were BCS. $29.18 \%$ of total patients could not specify their disease stage. Patients who were referred for pre-cancerous lesions were excluded.

\begin{tabular}{|c|c|c|}
\hline $\begin{array}{l}\text { Serial } \\
\text { No. }\end{array}$ & Items & Result $^{\top}$ \\
\hline I & Patient Characteristic & \\
\hline la & Stage 1 & $13.63 \%$ \\
\hline Ib & Stage 2 & $13.63 \%$ \\
\hline Ic & Stage 3 & $12.7 \%$ \\
\hline Id & Stage 4 & $16.36 \%$ \\
\hline le & Breast cancer survivor & $14.5 \%$ \\
\hline If & Disease stage unspecified & $29.18 \%$ \\
\hline II & Current understanding of your condition & \\
\hline 1 & How do you describe your current knowledge about your condition? & \\
\hline $1 \mathrm{a}$ & Adequate & $90.9 \%$ \\
\hline $1 \mathrm{~b}$ & Not adequate & $6.4 \%$ \\
\hline 1c & Not sure & $2.7 \%$ \\
\hline 2 & Answer question related to your condition. & \\
\hline $2 a$ & Able to record diagnosis & $61.8 \%$ \\
\hline $2 \mathrm{~b}$ & Current treatment & $85 \%$ \\
\hline $2 c$ & Stage & $55.45 \%$ \\
\hline
\end{tabular}




\section{Cureus}

2d Aware of prognosis

2d1. Good $30.9 \%$

$\begin{array}{ll}\text { 2d2. Bad } & 8.19 \%\end{array}$

$\begin{array}{ll}\text { 2d3. Not aware } & 59 \%\end{array}$

$3 \quad$ Would you like to be more educated?

$\begin{array}{llr}\text { 3a } & \text { Yes } & 32.7 \%\end{array}$

$\begin{array}{lll}3 b & \text { No } & 64.5 \%\end{array}$

$4 \quad$ Which of the following components you think need more education about?

$\begin{array}{lll}4 a & \text { Risk factors and genetics } & 11.8 \%\end{array}$

4b Prognosis $26.3 \%$

$\begin{array}{ll}4 c & \text { Complication }\end{array} 2.5 \%$

$\begin{array}{ll}4 \mathrm{~d} & \text { Treatment options and side- effects } \\ \end{array}$

III Psychological and social aspects

$5 \quad$ Do you have any of the following as result of the condition and/ or treatment?

$\begin{array}{lll}5 a & \text { Anxiety } & 44.5 \%\end{array}$

$\begin{array}{llr}5 b & \text { Fear } & 27.3 \%\end{array}$

$\begin{array}{llr}5 c & \text { Uncertainty } & 27.3 \%\end{array}$

5d Sadness $21.8 \%$

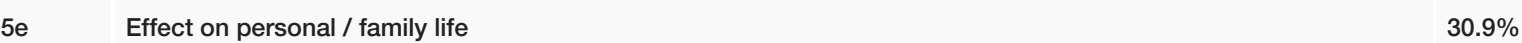

$\begin{array}{llr}5 f & \text { Effect on work performance } & 23.6 \%\end{array}$

$\begin{array}{lll}5 \mathrm{~g} \quad \text { Other issues } & 1.8 \%\end{array}$

$6 \quad$ Do you want your oncologist to initiate discussions regarding above issues?

$\begin{array}{lll}6 a & \text { Yes } & 22.73 \%\end{array}$

$\begin{array}{lll}6 \mathrm{~b} & \text { No } & 77.27 \%\end{array}$

$7 \quad$ What would you want your oncologist to do if you face such issues?

$\begin{array}{lll}7 a & \text { Manage them } & 57 \%\end{array}$

$\begin{array}{ll}7 \mathrm{~b} \quad \text { Let your PCP manage } & 10 \%\end{array}$

$\begin{array}{lll}7 c & \text { Referral to psychotherapist } & 9.01 \%\end{array}$

$\begin{array}{ll}7 d \quad \text { Referral to social worker } & 11.8 \%\end{array}$

$\begin{array}{lll}7 \mathrm{e} & \text { Referral to nurse navigator } & 13.6 \%\end{array}$

IV Physical symptoms related to your condition

$8 \quad$ Do you currently have following symptoms related to your condition or treatment?

$\begin{array}{lll}8 \mathrm{a} & \text { Pain } & 25.45 \%\end{array}$

$\begin{array}{ll}8 b \quad \text { Fatigue } & 41.8 \%\end{array}$

$\begin{array}{llr}8 \mathrm{c} & \text { Nausea } & 18.18 \%\end{array}$

8d Vomiting $\quad 4.54 \%$

$\begin{array}{lll}8 \mathrm{e} & \text { Other } & 3.63 \%\end{array}$

$9 \quad$ Do you think there is a need to pay more attention to these symptoms in subsequent visits?

9a Yes 


\section{Cureus}

\begin{tabular}{|c|c|c|}
\hline $9 \mathrm{~b}$ & No & $67.27 \%$ \\
\hline V & End of life care planning & \\
\hline 10 & Do you think end of life care discussions with your oncologist is an integral component of your overall care? & \\
\hline $10 a$ & Response from patients in adjuvant treatment group (early to advanced stage disease) & \\
\hline 10ai & Yes & $34.09 \%$ \\
\hline 10aii & No & $65.91 \%$ \\
\hline $10 \mathrm{~b}$ & Response from patient with metastatic disease & \\
\hline 10bi & Yes & $44.5 \%$ \\
\hline 10bii & No & $55.5 \%$ \\
\hline $10 \mathrm{c}$ & Response from breast cancer survivors & \\
\hline $10 \mathrm{ci}$ & Yes & $43.75 \%$ \\
\hline 10cii & No & $56.25 \%$ \\
\hline 11 & Have you ever had a discussion about end of life care planning with your oncologist? & \\
\hline $11 \mathrm{a}$ & Yes, and within 12 months & $4.5 \%$ \\
\hline 11b & Yes, but not within 12 months & $10.9 \%$ \\
\hline $11 \mathrm{c}$ & Never & $89 \%$ \\
\hline 12 & $\begin{array}{l}\text { Please select components (multiple) of the end of life care planning you think need to have discussion with your } \\
\text { oncologist? }\end{array}$ & \\
\hline $12 a$ & Prognosis & $27.27 \%$ \\
\hline $12 \mathrm{~b}$ & Life expectancy & $26.36 \%$ \\
\hline 12c & Effect of treatment on quality of life & $22.7 \%$ \\
\hline $12 \mathrm{~d}$ & Your preference on extending survival vs quality of life & $22.7 \%$ \\
\hline $12 \mathrm{e}$ & Palliative care & $9 \%$ \\
\hline $12 f$ & Hospice & $10.9 \%$ \\
\hline $12 \mathrm{~g}$ & Advance directive & $11.8 \%$ \\
\hline $12 \mathrm{~h}$ & Involvement of family in decision making & $13.6 \%$ \\
\hline 13 & When would you want to have these discussions? & \\
\hline $13 a$ & Response from patients in adjuvant treatment group (early to advanced stage disease) & \\
\hline 13ai & At diagnosis/ initiation of treatment & $6.8 \%$ \\
\hline 13aii & When oncologist think it's appropriate & $72.7 \%$ \\
\hline 13aiii & When you request it & $15.9 \%$ \\
\hline 13aiv & When it may affect treatment plan & $11.3 \%$ \\
\hline 13b & Response from patients with metastatic disease & \\
\hline $13 b i$ & At diagnosis/ initiation of treatment & $16.6 \%$ \\
\hline 13bii & When oncologist think it's appropriate & $44.44 \%$ \\
\hline 13biii & When you request it & $44.44 \%$ \\
\hline 13biv & When it may affect treatment plan & $11.11 \%$ \\
\hline $13 \mathrm{c}$ & Response from breast cancer survivor & \\
\hline $13 \mathrm{ci}$ & At diagnosis/ initiation of treatment & $12.5 \%$ \\
\hline 13cii & When oncologist think it's appropriate & $50 \%$ \\
\hline
\end{tabular}




\section{Cureus}

13 ciii

When you request it

13civ When it may affect treatment plan

How frequently?

$14 a$

Once

$14 \mathrm{~b}$

$14 \mathrm{c}$

\section{TABLE 1: Detailed result of the survey}

Please note all responses may not add up to exactly $100 \%$ because many patients chose not to answer or chose multiple answers in certain questions.

\section{Self-reported knowledge by a patient}

About $90.9 \%$ of our patients mentioned that they have adequate knowledge about their condition, $2.7 \%$ reported that they are not sure about their current understanding of the disease while $6.4 \%$ felt that their knowledge about their disease is not adequate. In actuality, only 55.45\% could identify the stage of their cancer, and out of them, only $16.3 \%$ could provide further tumor characteristics. Interestingly, $85 \%$ of patients were aware of their treatment plans. 32.7\% of our patients desired more education and information about their condition. $11.8 \%$ wanted to know more about risk factors, $26.3 \%$ about prognosis, $24.5 \%$ about complications, and $29 \%$ about various available treatment options.

\section{Psychological and social aspects}

Overall, $44.5 \%$ of patients suffered from anxiety, $27.3 \%$ were fearful about recurrence, and $27.3 \%$ had concerns related to uncertainty about their future; $23.6 \%$ of patients mentioned that their work is being affected because of their physical condition; $77.27 \%$ of our patients did not want their oncologist to initiate a discussion about these psychosocial issues. However, 57\% of them expected their oncologist to manage those symptoms if already diagnosed and $10 \%$ of them wanted their primary care physician (PCP) to manage those symptoms.

\section{Physical symptoms}

Cancer-related fatigue was reported by $41.8 \%$ of patients, pain by $25.45 \%$. Other symptoms that were commonly reported were nausea, joint pain, peripheral neuropathy, mouth sores, etc. For our cohort, $67.27 \%$ of patients mentioned that they did not feel the necessity for these symptoms to be discussed in subsequent visits, apparently, they were adequately managed.

\section{EoL care planning}

There were $34.09 \%$ of patients in the early stage of cancer, $44.5 \%$ in advanced stages of breast cancer, and $43.75 \%$ of BCS mentioned that they had EoL discussion with their oncologist. For those who had EoL discussion with their oncologist, they consider prognosis (27.27\%), life expectancy (26.36\%), the effect of treatment on quality of life, and functional status (22.7\%) as the major topics to be focused on.

We noticed a difference between different patient groups regarding their preference for EoL care discussion. Among patient subgroups with early-to-advanced-stage disease on adjuvant treatment, $72.7 \%$ wanted this discussion at regular intervals decided by their oncologist, $6.8 \%$ wanted it at fixed intervals, $15.9 \%$ would prefer discussion when they desired and $11.3 \%$ would want it when there is a change in the treatment plan. In the BCS cohort, the majority of them (56\%) also wanted to leave this discussion to their oncologist's discretion.

Patients with metastatic disease (18 patients) in response to EoL care discussion questions responded in the following fashion. $16.66 \%$ desire discussion at regular intervals, $44.44 \%$ desire discussion at oncologist discretion, $44.44 \%$ desire discussion when they want, $11.11 \%$ desire discussion at the time of change of therapy. As some patients responded to multiple choices, the percentage did not add up to $100 \%$.

We asked our patients to rate the overall care they are receiving at our clinic on a scale of $1-10$, while 1 being the worst and 10 being the best experience. We achieved an aggregate score of 9.22 .

To adjudge the appropriateness of our survey, we asked our patients for a response as to whether they felt this survey might help improve their care and communication between their oncologists and them. We received an aggregate rating of 7.93 on the same scale of 1-10. 
We also wanted to know if the survey or any of its components caused them any distress. $84.5 \%$ of patients were unbothered while $9 \%$ of them were distressed because of some survey questions, mostly related to EoL questions. $6.5 \%$ of total patients did not respond to this question.

\section{Discussion}

In addition to the actual diagnosis of breast cancer, patient's knowledge of the specifics of their breast cancer such as stage, prognosis, therapeutic options can be critical to the quality of their journey through their disease. We encountered a disparity between actual knowledge and perceived knowledge in our patients. Patient's understanding of their condition modified goals of care and also defined their expectations from their HCP. With a surge in survivorship with the advancement in diagnosis and treatment of cancer, it is imperative that HCP understand the needs and perspectives of their patients of that they solicit the participation of their patients as well. There may be unidentifiable barriers that could limit their ability to relay their concerns. We designed a survey-based study to capture the concerns of these patients, their unmet needs, identify gaps in care, and improve overall patient satisfaction and outcomes. We also tried to analyze the problem from both the patient and physician perspectives.

As our study revealed, patients self-reported knowledge was high at $90.9 \%$ but their actual understanding of their disease, staging, and prognosis appeared less and therefore, contradictory. Our findings are consistent with prior studies [4]. Low educational state, low health literacy, ethnicity, the language barrier could all contribute but is beyond the scope of our research. Improving patient education may lead to better-informed decisions and better adherence to treatment plans. Studies have been previously done to evaluate if increased information access reduced distress in cancer patients [5]. As per Vogel et al. (2008), patients having breast cancer who were given information had a decreased level of anxiety and feeling of insecurity [6]. $80 \%$ of our cohort requested more information with the majority of them having concerns related to prognosis, future complications, and treatment options. Exploring further patient's concerns and providing supportive care could be attempted through various methods including internet-based education, telephone counseling, involving breast health specialists, and navigator in care $[7,8]$.

We reached an intriguing conclusion about the role of oncologists in the psychosocial well-being of breast cancer patients. $77.27 \%$ of all our patients preferred their oncologist not to initiate discussion on psychosocial issues, however, $55.27 \%$ of the $77.27 \%$ would want their oncologists to address those issues if they already have been diagnosed with any psychosocial issues. What does that mean? Cancer patients may have multiple psychological issues that can go undetected or be attributed to adjustment, grief, or stress. Some patients who have lower cancer-related health education also tend to minimize their symptoms which can have quite a serious impact including depression, suicidal tendencies, refusal of treatment in advanced cases, etc. $[8,9]$. Patients might not request the additional provision of information when they have knowledge gaps. During the clinical encounter, clinical practitioners should assess the individual educational needs and tailor the education accordingly. Health care providers should continue assessing the informational needs of a patient during different stages of the treatment, realizing at the beginning patients' and families can be overwhelmed by the information provided. This can lead to misunderstanding the information and new questions may emerge along the treatment process.

As there is generally a strong relationship between oncologists and patients, patients often presume their oncologist would address any symptoms related to the cancer diagnosis. Oncologists, on the other hand, may feel poorly equipped to handle general health issues or not related to cancer and may expect the participation of the PCP for those issues. It's quite possible that patients may confuse the role of their physicians. Our study emphasizes a need for better coordination of care among physicians. Lack of clear guidelines to the patient of which physician is responsible for which symptoms may compromise comprehensive care [10]. Practical tools such as the Hospital and Anxiety Depression Scale (HADS) and the Brief Symptom Inventory (BSI) have also been shown to be helpful to monitor psychological states across the disease trajectory [11]. However, this needs better coordination of care between HCPs. Some studies have shown that there is a disconnect between patient and physician, among physicians (PCP, oncologist, other subspecialties) as well which may lead to gaps in care [11-14].

Another spectrum of patient education is the EoL care discussion. Patients who are not well aware of their tumor staging and prognosis may fail to understand the importance of EoL care discussion and palliative care which may complicate care moving forward. As per one study, physicians tend to withhold information if a patient has a poor prognosis concerned that their patient may lose hope in treatment $[15,16]$. Patients who have a relatively lower level of understanding of their disease process may think in a similar fashion. Oncologists play a critical role in caring for a patient with cancer through treatment and in some cases to the EoL [16,17]. In our study, we found that only $44.5 \%$ of our patients with advanced disease wanted to have EoL discussion while $55.5 \%$ deferred it. Lack of proper cancer knowledge may lead to a lower desire for disease information due to a higher preference for a passive decision-making approach, being less autonomous in regards to decisions of medical care. EoL care discussion may provide a more realistic insight into their condition, especially in advanced cancer patients. It should include discussion of comprehension of prognosis, life expectancy, treatment options, side effects of treatment, quality of life. As per Saraiya et al. (2008), improvements in patient decision making and clinical practice can reduce the burden of symptoms for patients if clinicians gain a better understanding of patient's expectations respecting the 
longer-term consequences of diagnosis and treatment [18]. Early integration of palliative care in cancer improves symptom control, end-of-life care, health-related communication, and continuity of care [19].

Breast cancer patients often experience complications related to the disease itself, chemotherapy, and surgery. Cancer-related fatigue is very common and affects work and daily performance [20,21]. Patients on aromatase inhibitor frequently experience pain, musculoskeletal symptoms among other side effects [22]. Chronic arm lymphedema after breast surgery impairs physical performance and studies have shown that early mobilization and rehabilitation have improved outcomes [23]. It is imperative that the patient's physical symptoms be addressed early and adequately as physical disability often leads to depression [24].

Our study has certain limitations and strengths. It's a single-center study with a relatively small study population. Our patients come from various ethnicities and backgrounds. However, we did not analyze our data in a way to accommodate cultural and ethnic variation in regards to their perspective towards disease and treatment. We propose a future multicenter study with a larger patient population with higher variation to validate our study. There can be a difference in patient perspective based on cancer type and prognosis which needs to be studied further. The final aim is to create a better method for the care of cancer patients tailored to their individual needs and eliminating gaps in care.

\section{Conclusions}

Our study attempts to measure the level of awareness related to breast cancer diagnosis and its complications among our patients and highlights its impact on their overall care. Management of breast cancer is not limited to therapeutic measures only but also includes psycho-social wellness and EoL care discussion, particularly for patients with metastatic disease. The psychosocial aspect of management remains poorly understood in clinical practice and relatively neglected and that the cause of this is multifactorial. Lack of clear guidelines and disconnect between patients and physician and among physicians themselves contribute to the gap in care. Patient education will lead to an improvement in communication between patient and physician and eventually improve outcomes. Through our research, we also tried to understand patient perspective in their care. The bigger question that remains unanswered is how to increase patient's involvement in their care at every step. We need better ways to improve the education, communication, and decision-making capacity of our patients. With the improvement in breast cancer survivorship, medical care of such patients is an emerging area for quality improvement.

\section{Additional Information \\ Disclosures}

Human subjects: Consent was obtained by all participants in this study. Monmouth Medical Center Institutional Review Board issued approval NA. waived . Animal subjects: All authors have confirmed that this study did not involve animal subjects or tissue. Conflicts of interest: In compliance with the ICMJE uniform disclosure form, all authors declare the following: Payment/services info: All authors have declared that no financial support was received from any organization for the submitted work. Financial relationships: All authors have declared that they have no financial relationships at present or within the previous three years with any organizations that might have an interest in the submitted work. Other relationships: All authors have declared that there are no other relationships or activities that could appear to have influenced the submitted work.

\section{References}

1. Cancer stat facts: female breast cancer. (2020). Accessed: June 12, 2020: https://seer.cancer.gov/statfacts/html/breast.html.

2. SEER cancer statistics review, 1975-2011. (2013). Accessed: June 12, 2020 http://seer.cancer.gov/csr/1975_2010/.

3. Perry S, Kowalski TL, Chang CH: Quality of life assessment in women with breast cancer: benefits, acceptability and utilization. Health Qual Life Outcomes. 2007, 5:24. 10.1186/1477-7525-5-24

4. Shim HY, Park JH, Kim SY, et al.: Discordance between perceived and actual cancer stage among cancer patients in Korea: a nationwide survey. PLoS ONE. 2014, 9:e90483. 10.1371/journal.pone.0090483

5. White V, Farrelly A, Pitcher M, Hill D: Does access to an information-based, breast cancer specific website help to reduce distress in young women with breast cancer? Results from a randomised trial. Eur J Cancer Care. 2018, $27:$ :e12897. 10.1111/ecc.12897

6. Vogel BA, Bengel J, Helmes AW: Information and decision making: patients' needs and experiences in the course of breast cancer treatment. Patient Educat Counsel. 2008, 71:79-85. 10.1016/j.pec.2007.11.023

7. Stephens PA, Osowski M, Fidale MS, Spagnoli C: Identifying the educational needs and concerns of newly diagnosed patients with breast cancer after surgery. Clin J Oncol Nurs. 2008, 12:253-58. 10.1188/08.CJON.253-258

8. Sutherland G, Hill D, Morand M, Pruden M, McLachlan SA: Assessing the unmet supportive care needs of newly diagnosed patients with cancer. Eur J Cancer Care. 2009, 18:577-84. 10.1111/j.13652354.2008.00932.x

9. Costas-Muniz R, Sen R, Leng J, Aragones A, Ramirez J, Gany F: Cancer stage knowledge and desire for information: mismatch in Latino cancer patients?. J Cancer Educ. 2013, 28:458-465. 10.1007/s13187-0130487-8 
10. Earle CC, Neville BA: Underuse of necessary care among elderly colorectal cancer survivors . Cancer. 2004, 101:1712-1719. 10.1002/cncr.20560

11. Advancing psychosocial care in cancer patients. (2017). Accessed: June 12, 2020: https://f1000research.com/articles/6-2083/v1.

12. Snyder CF, Earle CC, Herbert RJ, Neville BA, Blackford AL, Frick KD: Preventive care for colorectal cancer survivors: a 5-year longitudinal study. J Clin Oncol. 2008, 26:1073-79. 10.1200/JCO.2007.11.9859

13. Snyder CF, Earle CC, Herbert RJ, Neville BA, Blackford AL, Frick KD: Trends in follow-up and preventive care for colorectal cancer survivors. J Gen Intern Med. 2008, 23:254-59. 10.1007/s11606-007-0497-5

14. Earle CC, Burstein HJ, Winer EP, Weeks JC: Quality of non-breast cancer health maintenance among elderly breast cancer survivors. J Clin Oncol. 2003, 21: 1447-51. 10.1200/JCO.2003.03.060

15. Sarafis P, Tsounis A, Malliarou M, Lahana E: Disclosing the truth: a dilemma between instilling hope and respecting patient autonomy in everyday clinical practice. Glob J Health Sci. 2014, 6:128-137. 10.5539/gihs.v6n1p128

16. Mack JW, Smith TJ: Reasons why physicians do not have discussions about poor prognosis, why it matters, and what can be improved. J Clin Oncol. 2012, 30:2715-17. 10.1200/JCO.2012.42.4564

17. Nipp RD, El-Jawahri A, Fishbein JN, et al.: The relationship between coping strategies, quality of life, and mood in patients with incurable cancer. Cancer. 2016, 122:2110-26. 10.1002/cncr.30025

18. Saraiya B. Bodnar-Deren S, Leventhal E, Leventhal H: End-of-life planning and its relevance for patients' and oncologists' decisions in choosing cancer therapy. Cancer. 2008, 113:3540-47. 10.1002/cncr.23946

19. Salins N, Patra L, Usha Rani MR, et al.: Integration of early specialist palliative care in cancer care: survey of oncologists, oncology nurses, and patients. Indian J Palliat Care. 2016, 22:258-265. 10.4103/09731075.185030

20. Mock V, Atkinson A, Barsevick A, et al.: NCCN practice guidelines for cancer-related fatigue. Oncology. 2000, 14:151-161.

21. Lipman AJ, Lawrence DP: The management of fatigue in cancer patients . Oncology. 2004, 18:1527-38.

22. Briot K, Tubiana-Hulin M, Bastit L, Kloos I, Roux C: Effect of a switch of aromatase inhibitors on musculoskeletal symptoms in postmenopausal women with hormone-receptor-positive breast cancer: the ATOLL (articular tolerance of letrozole) study. Breast Cancer Res Treat. 2010, 120:127-134.

23. Binkley JM, Harris SR, Levangie PK, et al.: Patient perspectives on breast cancer treatment side effects and the prospective surveillance model for physical rehabilitation for women with breast cancer. Cancer. 118:2207-16. 10.1002/cncr.27469

24. Weber D, O'Brien K: Cancer and cancer-related fatigue and the interrelationships with depression, stress, and inflammation. J Evid Based Complementary Altern Med. 2017, 22:502-512. 10.1177/2156587216676122 